Review

\title{
Choline PET and PET/CT in Primary Diagnosis and Staging of Prostate
}

\section{Cancer}

\author{
S. Schwarzenböck ${ }^{1}$, M. Souvatzoglou ${ }^{2}$, B. J. Krause ${ }^{1 凶}$ \\ 1. Department of Nuclear Medicine, Universitätsmedizin Rostock, Universität Rostock, Rostock, GERMANY \\ 2. Department of Nuclear Medicine, Klinikum rechts der Isar, Technische Universität München, Munich, GERMANY
}

$\triangle$ Corresponding author: Department of Nuclear Medicine, Universitätsmedizin Rostock, Universität Rostock, Gertrudenplatz 1, 18057 Rostock, GERMANY. Phone: +49 (0)381 494 9101; Fax: $+49 \quad$ (0)381 $494 \quad 9102$; Mail: bernd.krause@med.uni-rostock.de

(ㅇ Ivyspring International Publisher. This is an open-access article distributed under the terms of the Creative Commons License (http://creativecommons.org/ licenses/by-nc-nd/3.0/). Reproduction is permitted for personal, noncommercial use, provided that the article is in whole, unmodified, and properly cited.

Received: 2011.12.23; Accepted: 2012.02.26; Published: 2012.03.15

\begin{abstract}
PET and PET/CT using $\left[{ }^{11} \mathrm{C}\right]$ - and $\left[{ }^{18} \mathrm{~F}\right]$-labelled choline derivates is increasingly being used for imaging of primary and recurrent prostate cancer. While PET and PET/CT with [ $\left.{ }^{11} \mathrm{C}\right]$ - and $\left[{ }^{18} \mathrm{~F}\right]$-labelled choline derivates in patients suffering from biochemical recurrence of prostate cancer has been examined in many studies that demonstrate an increasing importance, its role in the primary staging of prostate cancer is still a matter of debate.

Morphological and functional imaging techniques such as CT, MRI and TRUS have demonstrated only limited accuracy for the diagnosis of primary prostate cancer. Molecular imaging with PET and PET/CT could potentially increase accuracy to localize primary prostate cancer. A considerable number of studies have examined the value of PET/CT with [ $\left.{ }^{11} \mathrm{C}\right]$ - and $\left[{ }^{18} \mathrm{~F}\right]-$ labelled choline derivates for the diagnosis of primary prostate cancer with mixed results. Primary prostate cancer can only be detected with moderate sensitivity using [ $\left.{ }^{\prime \prime} \mathrm{C}\right]-$ and $\left[{ }^{18} \mathrm{~F}\right]$ choline PET and PET/CT. The detection rate depends on the tumour configuration. Detection is also limited by a considerable number of microcarcinomas that cannot be detected due to partial volume effects. Therefore small and in part rind-like tumours can often not be visualized. Furthermore, the differentiation between benign changes like prostatitis, high-grade intraepithelial neoplasia (HGPIN) or prostatic hyperplasia is not always possible. Therefore, at the present time, the routine use of PET/CT with $\left[{ }^{11} \mathrm{C}\right]-$ and $\left[{ }^{18} \mathrm{~F}\right]$-labelled choline derivates cannot be recommended as a first-line screening procedure for primary prostate cancer in men at risk. A potential application of choline PET and PET/CT may be to increase the detection rate of clinically suspected prostate cancer with multiple negative prostate biopsies, for example in preparation of a focused re-biopsy and may play a role in patient stratification with respect to primary surgery and radiation therapy in the future.
\end{abstract}

Key words: choline PET, PET/CT, Prostate Cancer

\section{Introduction}

Prostate cancer is currently the highest prevalent form of cancer in men $(192,280$ cases, $25 \%$ of all incident cases) and the second most common cause of cancer associated deaths (9\%) in the USA [1-2]. The gold standard for diagnosing prostate cancer is histopathological examination of prostate tissue obtained by prostate needle biopsy. Commonly used diagnostic tools in the evaluation of prostate cancer are digital 
rectal examination, measurement of serum levels of prostate specific antigen (PSA), transrectal ultrasound (TRUS) as well as TRUS-guided biopsies [2]. Beside these diagnostic modalities, morphological and functional imaging methods such as computed tomography (CT), magnetic resonance imaging (MRI), bone scintigraphy and positron emission tomography (PET, PET/CT) are also used.

Morphological imaging techniques such as TRUS, CT and MRI have demonstrated only limited accuracy for primary diagnosis of prostate cancer, recurrent disease as well as advanced disease. Concerning diagnosis of primary prostate cancer, CT has shown limited specificity. Furthermore the detection of lymph node metastases is limited by morphological imaging such as CT and MRI; first, small lymph node metastases cannot be visualized; second, size as only criterion might not be sufficient to detect metastatic involvement in lymph nodes. For the detection of bone metastases, CT may be of use in imaging trabecular changes caused by metastasis which appear relatively late in the course of bone metastases. Therefore increasing the diagnostic performance in prostate cancer imaging remains a major challenge. Combined molecular and morphological imaging techniques such as PET/CT may improve the diagnostic accuracy in imaging prostate cancer.

PET/CT based on increased glycolysis using $\left[{ }^{18} \mathrm{~F}\right]$ fluorodeoxyglucose (FDG) has shown only limited sensitivity for the detection of differentiated prostate carcinomas and imaging of recurrent prostate cancer in various studies [3-5]. Increased FDG uptake and accumulation is regularly only found in dedifferentiated, aggressive and metastasized prostate cancer. Other PET- and PET/CT tracers have been introduced for diagnosing prostate carcinoma based on an increased androgen receptor expression $\left(\left[{ }^{18} \mathrm{~F}\right]\right.$ fluorodihydrotestosterone (FDHT)), fatty acid synthesis ([11C]acetate), amino acid transport and protein synthesis $\left(\left[{ }^{11} \mathrm{C}\right]\right.$ methionine) as well as choline turnover by $\left[{ }^{11} \mathrm{C}\right]-/\left[{ }^{18} \mathrm{~F}\right]$ labelled choline derivates [5-11]. Promising results have been obtained for the use of PET- and PET/CT with $\left[{ }^{11} \mathrm{C}\right]-$ and $\left[{ }^{18} \mathrm{~F}\right]-$ labelled choline derivates, for an overview see Krause et al. [12]. The use of choline for imaging prostate cancer is based on increased phosphorylcholine levels and an elevated phosphatidylcholine turnover in prostate cancer cells [13-14]. After uptake into the tumor cell through a high affinity transporter system, choline is metabolized by choline kinase - which is the first step of the Kennedy pathway - and is incorporated into the phosphatidyl membrane. Key enzymes of the choline metabolism, like choline kinase, are up-regulated in prostate cancer cells [15-16]. Additionally, an in- creased expression of choline transporters and an elevated choline transportation rate have been described [16-19].

The use of $\left[{ }^{11} \mathrm{C}\right]-$ and $\left[{ }^{18} \mathrm{~F}\right]$-labelled choline derivates for the detection of primary prostate cancer has been examined in many studies with conflicting results, for an overview see Souvatzoglou et al. [20]. While some studies with selected patient groups demonstrated high sensitivities for the detection of primary prostate cancer [21-23], other studies reported lower detection rates [24-28]. Importantly the detection rate of primary prostate cancer using $\left[{ }^{11} \mathrm{C}\right]-$ and $\left.{ }^{18} \mathrm{~F}\right]$ choline-PET/CT is influenced by the tumor configuration with small and partly 'rind-like` carcinomas (onion ring form of growth) often not detected [28]. Furthermore, choline PET/CT has shown limited specificity.

This article reviews the use of PET and PET/CT using molecular imaging probes in prostate cancer with special emphasis on the use of radiolabeled choline derivates for diagnosis and staging of patients with primary prostate cancer.

\section{Diagnosis of primary prostate cancer CT}

Morphological imaging techniques such as TRUS, CT and MRI have demonstrated only limited accuracy for diagnosis of primary prostate cancer. Regarding the diagnosis of primary prostate cancer, CT cannot differentiate benign from malignant prostatic tissue; therefore the specificity in differentiating malignant from benign prostatic lesions is limited [14]. For lymph node staging CT has also shown limited sensitivity (36\% in a meta-analysis) [29].

At present, CT imaging has no decisive role in the diagnosis of primary prostate cancer [30]. The use of CT imaging is recommended for patients at high risk with a PSA level $>20 \mathrm{ng} / \mathrm{ml}$, Gleason score $>7$ and/or clinical tumor stage T3 or higher [31] or for detection of lymph node metastases and lymph node staging [30].

\section{MRI}

For detection, localization and definition of local extent of prostate cancer morphological and functional MRI techniques are increasingly being used. In T2-weighted MRI, prostate cancer tissue normally presents with a decreased signal intensity compared to the high signal intensity of the normal peripheral zone [30]. The detection rate of primary prostate cancer using MRI is superior compared to DRE and TRUS [32]. This result was corroborated by Hricak et al. (2007) who reported that MRI imaging performed better than CT, DRE and TRUS in the evaluation of 
uni- or bilateral disease of stage T2 and T4 [33] with sensitivity of $80 \%$ and specificity of $99 \%$ for detection of seminal vesicle invasion. Determination of the local tumor stage can be improved by using high resolution endorectal coil MRI [34]. Bloch et al. (2007) reported sensitivity between $75 \%$ and $89 \%$ for the determination of extracapsular extension with high-spatial-resolution dynamic contrast-enhanced and T2-weighted MRI [35]. High resolution endorectal coil MRI is recommended for use as an additional imaging modality in patients with negative biopsy and suspected primary prostate cancer and patients with a medium or high probability of extraprostatic disease [36].

Recent studies have evaluated functional and molecular MRI techniques for primary and nodal staging of prostate cancer such as diffusion weighted imaging (DWI) and dynamic-contrast-enhanced MRI as well as magnetic resonance spectroscopy (MRS). In some studies multiparametric MRI modalities were compared with choline PET/CT imaging.

Wefer et al. compared the accuracy of endorectal MRI and MRS with that of sextant biopsy for the sextant localization of prostate cancer. For sextant localization of prostate cancer, MRI and MRS were more sensitive but less specific than biopsy $(67 \%$ and $76 \%$ versus $50 \%$, and $69 \%$ and $68 \%$ versus $82 \%$, respectively). The sensitivity of sextant biopsy was significantly lower in the prostate apex than in the mid prostate or prostate base $(38 \%$ versus $52 \%$ and $62 \%$, respectively). These results showed that MRI and MRS had an accuracy similar to biopsy for intraprostatic localization of cancer and that they were more accurate than biopsy in the prostate apex [37]. Mazaheri et al. reported that combined MRS and DWI MRI improved differentiation between prostate cancer and prostatitis, especially in the peripheral zone [38]. Testa et al. compared the diagnostic performance of MRI, 3-dimensional MRS, combined MRI and MRS and $\left[{ }^{11} \mathrm{C}\right]$ choline for imaging primary prostate cancer. The authors showed that the sensitivity of $\left[{ }^{11} \mathrm{C}\right]$ choline PET/CT was lower in comparison to MRS and MRI combined with MRS (sensitivity of 55\% for [11C]choline PET/CT, 54\% for MRI and $81 \%$ for MRS, respectively) [39]. On contrary, Yamaguchi et al. reported a higher sensitivity of $\left[{ }^{11} \mathrm{C}\right]$ choline PET compared to MRI only and MRI/MRS in the detection of primary prostate cancer $(100 \%$ for PET, $60 \%$ for MRI and $65 \%$ for MRI/MRS) [23]. Eschmann et al. (2007) compared $\left[{ }^{11} \mathrm{C}\right]$ choline PET/CT with whole-body MRI for staging prostate cancer. The authors reported sensitivity and specificity of $97 \%$ and $77 \%$, respectively, for choline PET/CT and 79\% and 94\%, respectively, for whole-body MRI [40].
The use of MRI with ultrasmall superparamagnetic iron oxide (USPIO) was reported to be significantly better than conventional MRI in differentiating benign from malignant lymph nodes and showed a high sensitivity in detection of prostate cancer lymph nodes [41].

Eiber et al. showed the feasibility of using DWI for detection of lymph node metastases in patients with primary prostate and recurrent prostate cancer with a diagnostic accuracy of $85.6 \%$ [42].

Beer et al. examined 14 prostate cancer patients with $\left[{ }^{11} \mathrm{C}\right]$ choline PET/CT and DWI comparing the functional parameters SUV in PET and Apparent Diffusion Coefficient (ADC) in DWI of lymph nodes in prostate cancer using a linear regression analysis. ADC values and SUV showed a moderate but highly significant inverse correlation $(r=-0.5144, p<0.0001)$. In lymph nodes with low ADC values, the dispersion of SUV was more pronounced. Moreover, a highly significant difference was observed for mean ADC values and SUV in lymph nodes considered as benign or malignant by follow-up/histopathology (ADC $1.60 \pm 0.24$ vs. $1.09 \pm 0.23 \times 10(-3) \mathrm{mm}(2) / \mathrm{s} ; \quad S U V$ $1.82 \pm 0.57$ vs. $4.68 \pm 03.12 ; \mathrm{p}<0.0001$, respectively) [43].

Based on the available literature, MRI imaging of prostate cancer is not routinely used in the diagnosis of primary prostate cancer at the present time. MRI can be useful for the evaluation of seminal vesicle infiltration and/or the diagnosis of extra-capsular spread with potential implications on staging and subsequent treatment. Furthermore, MRI may be useful as additional diagnostic tool in patients with multiple negative biopsies. In patients with high risk prostate cancer, an MRI (or CT) can be useful if the decision on the therapeutic strategy is under way.

\section{FDG}

The use of $\left.{ }^{[18} \mathrm{F}\right]$ fluorodeoxyglucose (FDG) in oncology is based on an increased glucose uptake in cancer cells by increased glucose transport through the cell membrane of malignant cells and an overexpression of the enzyme hexokinase. In the diagnosis of primary and metastatic prostate cancer, FDG PET/CT imaging has shown limited efficacy due to FDG uptake both in prostate cancer cells and benign prostatic tissue such as benign prostatic hyperplasia [44-45]. Liu et al. (2001) and Hofer et al. (1999) showed a limited value for FDG-PET concerning differentiation of prostate hyperplasia, prostate carcinoma and local recurrence $[3,46]$. Relatively low FDG uptake has been attributed to a relatively slow metabolic rate with a lower expression of glucose transport proteins of prostate cancer cells in comparison to other cancers. 
There is a relationship between differentiation of prostate cancer cells and FDG uptake: low differentiated prostate cancer cells show higher FDG uptake in comparison to higher differentiated prostate cancer cells (Fig. 1). FDG shows renal excretion which leads to activity accumulation in the ureters and the bladder potentially obscuring the target organ and the adjacent tissues like seminal vesicles, hampering the detection of prostate cancer [47]. Oyama et al. (1999) reported a sensitivity of $64 \%$ in detection of primary prostate cancer with a tendency for higher FDG uptake in tumors with higher Gleason score [48]. This result was confirmed by Melchior et al. (1999) who reported higher FDG accumulation in poorly differentiated prostate cancer than in low grade prostate cancer [49]. Additionally, Jadvar et al. demonstrated that FDG uptake was higher in androgen-independent than androgen-sensitive human prostate cancer xenografts and androgen ablation caused a significant decrease in tumor FDG uptake of about 55\% [50], suggesting that higher FDG accumulation may not only be observed in androgen-independent tumors in comparison to androgen-sensitive tumors but also that androgen may also have a modulatory effect on the glucose metabolism of androgen-sensitive prostate cancer [45]. Schöder and Larson have summarized possible explanations for the poor performance of FDG PET/CT in primary diagnosis of prostate cancer: a relatively low metabolic rate, location of the prostate adjacent to the urinary bladder and lack of appropriate patient selection [51].
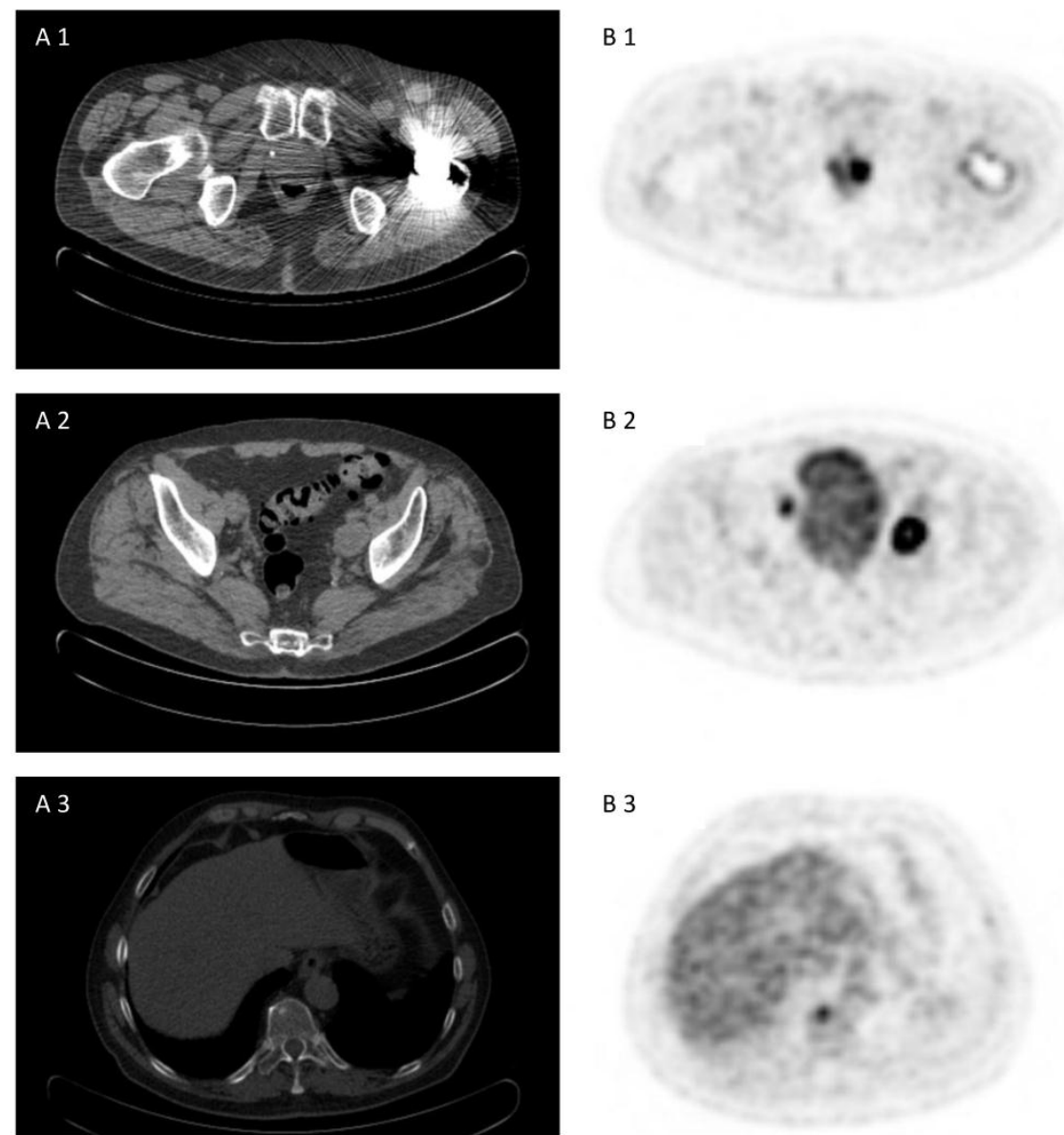
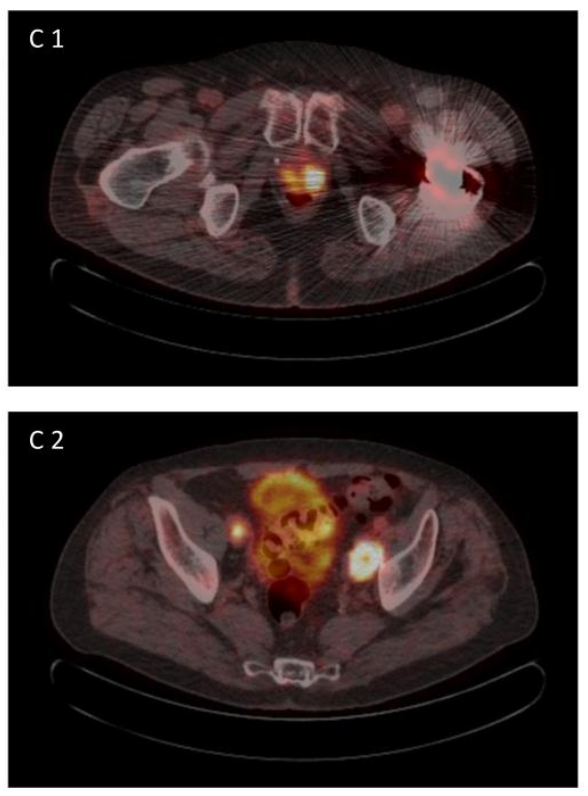

Fig. I. 72 year old patient with biopsy proven prostate cancer, PSA 7,38 ng/ml, referred for [ $\left.{ }^{18} \mathrm{~F}\right] \mathrm{FDG}$ PET/CT for primary staging. $\left[{ }^{18} \mathrm{~F}\right]$ FDG PET/CT revealed advanced disease of primary prostate cancer, iliacal lymph node metastases and bone metastasis (A I-3) CT scan, (B I-3) PET scan, (C I-3) PET/CT fused images. 


\section{ACETATE}

[11C]acetate uptake in tumor cells is related to an enhanced lipid synthesis, reflecting the increased lipid synthesis during tumor growth of cancer cells [52]. An increase in fatty acid synthesis and an overexpression of the key enzyme fatty acid synthase have been demonstrated in prostate cancer cells [53]. In a comparative study by Oyama et al. $\left[{ }^{11} \mathrm{C}\right]$ acetate proved to be superior to $\left[{ }^{18} \mathrm{~F}\right] \mathrm{FDG}$ for imaging prostate cancer [54]. However, $\left[{ }^{11} \mathrm{C}\right]$ acetate is not a cancer-specific tracer and also accumulates in normal and hyperplastic tissue. Kato et al. (2002) showed that there was a significant overlap of uptake in normal prostate, benign prostate hyperplasia and prostate cancer [55]. Wachter et al. (2006) showed that combined PET/CT imaging or PET/MRI imaging may be helpful in defining the exact anatomical localization and classification of acetate PET findings [56]. A recent study showed a limited accuracy of $71 \%$ in the detection of prostate cancer and a lack of information on cancer aggressiveness using $\left[{ }^{11} \mathrm{C}\right.$ ]acetate PET/CT [57].

At the moment the use of $\left[{ }^{11} \mathrm{C}\right]$ acetate PET/CT is not recommended in the diagnosis of primary prostate cancer.

\section{METHIONINE}

Uptake of $\left[{ }^{11} \mathrm{C}\right]$ methionine is related to an increased amino acid transport and protein synthesis of cancer cells. There are only few studies evaluating the use of $\left[{ }^{11} \mathrm{C}\right]$ methionine PET/CT in imaging prostate cancer. Nunez et al. compared FDG-PET and $\left[{ }^{11} \mathrm{C}\right]$ methionine PET and reported a higher detection for $\left[{ }^{11} \mathrm{C}\right]$ methionine in comparison to FDG [5]. Shiiba et al. evaluated the potential of $\left[{ }^{11} \mathrm{C}\right]$ methionine PET/CT and ${ }^{18}{ }^{18} \mathrm{~F}$ FDG PET/CT to diagnose primary prostate cancer. $\mathrm{SUV}_{\max }$ was compared with the pathological findings. The authors divided the tumors into three groups. If the summed Gleason score of the specimens was 5 or less, they were grouped as NG (no grade with the Gleason score). If the summed Gleason score was 6 or 7, the tumors were defined as LG (low Gleason score group), and if the summed Gleason score was 8,9 or 10 , the tumors were classified as HG (high Gleason score group). There was no significant difference between $\left.{ }^{[11} \mathrm{C}\right]$ methionine and $\left.{ }^{18} \mathrm{~F}\right] \mathrm{FDG}$ PET/CT in diagnosing prostate cancer of high Gleason score $(\geq 8)$. Therefore, $\left[{ }^{11} \mathrm{C}\right]$ methionine appeared to be useful for detecting prostate cancer of both low and high Gleason score [58].

However, further studies are needed to assess the value of $\left[{ }^{11} \mathrm{C}\right]$ methionine PET/CT in diagnosing primary prostate cancer.

\section{FDHT}

$\left[{ }^{18} \mathrm{~F}\right]$ fluorodihydrotestosterone (FDHT) is another innovative PET tracer that has been introduced for imaging prostate cancer. PET/CT imaging using FDHT is based on an increased androgen receptor expression. However, expression of androgen receptors is similar in prostate cancer cells compared to normal prostate cells. Therefore, $\left[{ }^{18} \mathrm{~F}\right] \mathrm{FDHT}$ might be more suitable for therapy monitoring than for diagnosing primary prostate cancer. Larson et al and Dehdashti et al. showed that testosterone might lead to a decrease of $\left[{ }^{18} \mathrm{~F}\right] \mathrm{FDHT}$ uptake in prostate cancer cells $[7,9]$.

\section{CHOLINE}

The value of PET and PET/CT using $\left[{ }^{11} \mathrm{C}\right]-$ and $\left[{ }^{18} \mathrm{~F}\right]-$ labeled choline derivates for the diagnosis of primary prostate cancer has been examined in several studies with partially controversial results $[8,11$, 21-27, 59-69] (Table 1). For detection of local prostate cancer mean values for sensitivity and specificity vary between $73 \%$ and $91 \%$ (Fig. 2 and 3). The majority of reported sensitivities were based on a patient-based analysis, which showed better results (98-100\%) than the lesion-based analysis. Some of the studies with a given selection of patient groups showed higher sensitivities for the detection of primary prostate cancer [21-23], while other studies reported lower detection rates [24-28].

The following studies reported a high sensitivity for the detection of primary prostate cancer using PET and PET/CT with radioactively labelled choline derivates. De Jong et al. prospectively evaluated the visualization of primary prostate carcinomas with $\left[{ }^{11} \mathrm{C}\right]$ Choline PET in patients with biopsy-proven prostate cancer in comparison with benign changes of the prostate. Normal prostate and prostate cancer tissue showed mean SUV of 2.3 (1.3-3.2) and 5 (2.4-9.5), respectively. In 24 of 25 patients there was a focal increased choline uptake [60]. Sutinen et al. examined 14 patients with histologically proven prostate cancer using $\left[{ }^{11} \mathrm{C}\right]$ Choline PET. In all 14 patients visualization and detection of primary prostate cancer was possible by means of an increased choline uptake [68]. Kwee et al. examined 17 patients using [18F]fluorocholine PET. Eleven of the 17 patients had bilateral positive findings in histopathology, 6 of 17 had unilateral positive findings. In all of these 6 patients showing unilateral disease the affected side could correctly be identified using a SUV $\mathrm{Sax}_{\max }$ cut-off of $>3.3$ [21]. Yamaguchi et al. compared [11C]choline PET with MRI and MRS regarding localization and evaluation of lesions in patients with prostate cancer. $\left.{ }^{[11} \mathrm{C}\right]$ choline PET identified 20 out of 20 primary 
prostate carcinomas (sensitivity $100 \%$ ) while the sensitivity for MRI and MRS were only $60 \%(12 / 20)$ and $65 \%(13 / 20)$, respectively. A weak linear correlation was found between SUV $V_{\max }$ and PSA values $(p<0.05)$ as well as between $S_{U V}$ max and the ratio of $\mathrm{Cho}+\mathrm{Cr} / \mathrm{Ci}(\mathrm{r}=0.49, \mathrm{p}<0.05)$. Relating to localization of the lesions [ ${ }^{11} \mathrm{C}$ ]choline PET was concordant in 13 patients (out of 16 patients that underwent total prostatectomy) with histopathological results while this was true for MRS in only $50 \%(8 / 16)$ of the cases [23]. Yoshida et al. evaluated the use of $\left[{ }^{11} \mathrm{C}\right]$ choline PET in staging primary prostate cancer. Primary prostate cancer could be identified by means of increased choline uptake in 5 of 6 patients (mean SUV of 4.21) (range 2.99 to 6.2), and only in one patient with primary prostate cancer could not be identified correctly using [ $\left.{ }^{11} \mathrm{C}\right]$ choline PET [69]. Reske et al. found a SUV $_{\max }$ cut-off of 2.65 with an associated area under the curve of $0.89 \pm 0.01$ in the ROC analysis for correct prediction of prostate cancer. Regions with prostate cancer could be identified in all patients $(26 / 26)$ using $\left[{ }^{11} \mathrm{C}\right]$ choline PET/CT, resulting in a sensitivity of $100 \%$. Furthermore the authors did not find a correlation between $\left[{ }^{11} \mathrm{C}\right]$ choline SUV and PSA value and Gleason-Score but found a correlation with $\mathrm{T}$ stage [22]. These results showing high sensitivities of choline PET/CT for the detection of primary prostate cancer could not be confirmed by a significant number of studies that reported limited sensitivities for primary staging of prostate cancer.

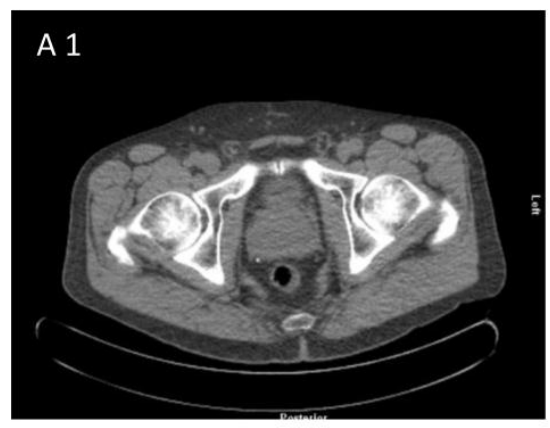

B 1
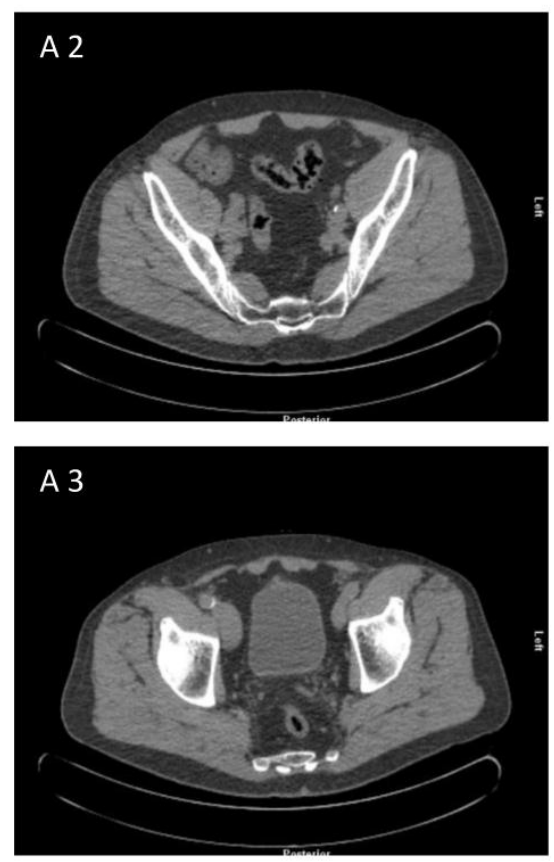

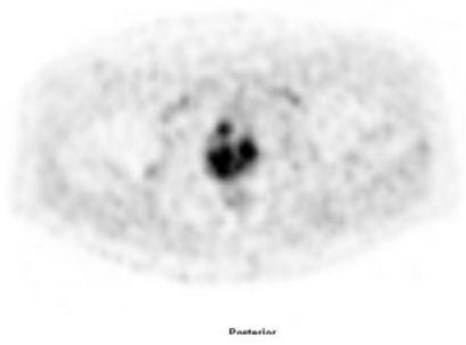

B 2

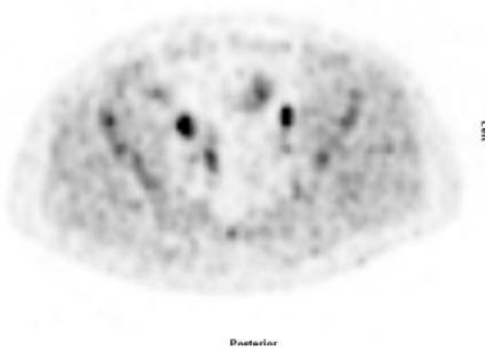

B 3



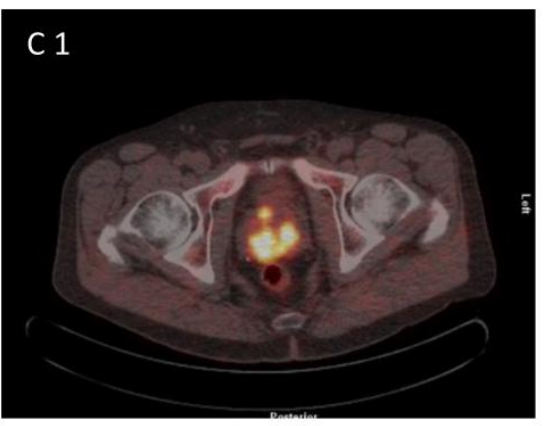
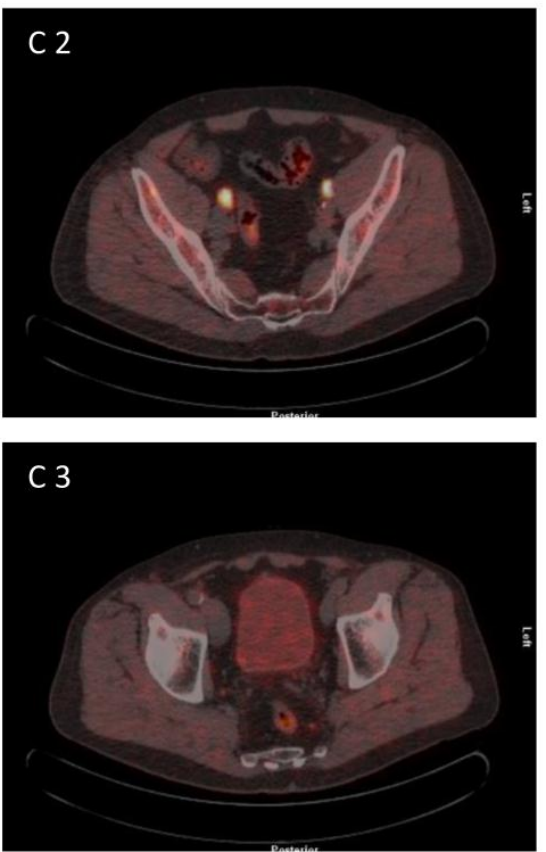

Fig. 2. 7I year old patient with biopsy proven prostate cancer, initial PSA $193 \mathrm{ng} / \mathrm{ml}$, referred for [18F]choline PET/CT for primary staging. $\left[{ }^{18} \mathrm{~F}\right]$ choline PET/CT revealed adcanced disease (primary prostate cancer, iliacal and pararectal lymph node metastases) (A I-3) CT scan, (B I-3) PET scan, (C I-3) PET/CT fused images. 


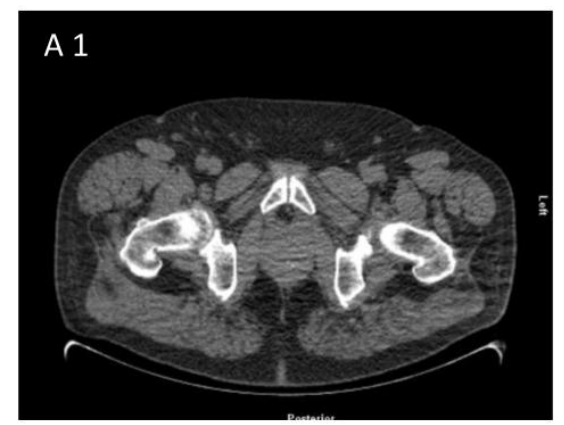

B 1
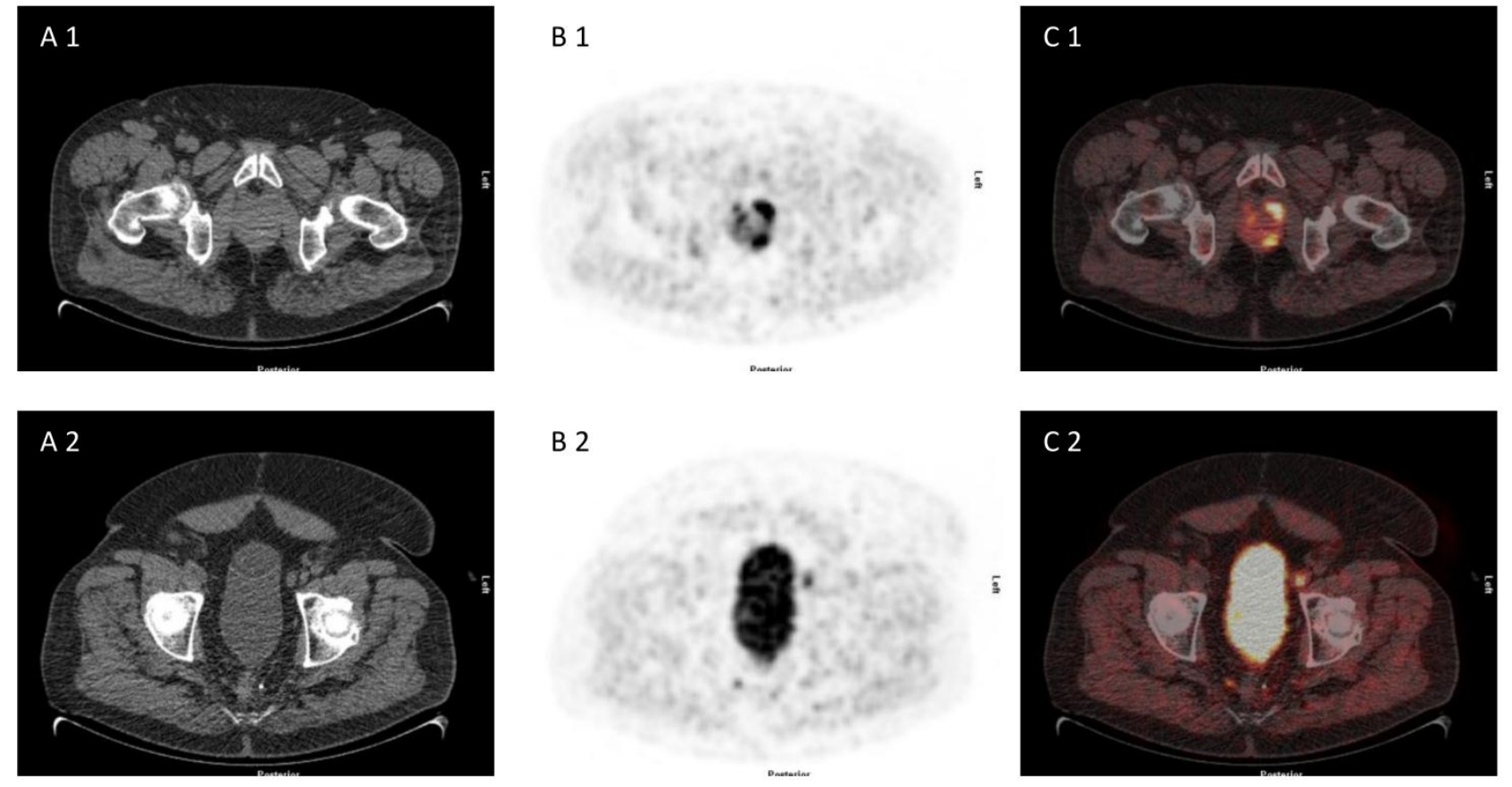

B 2
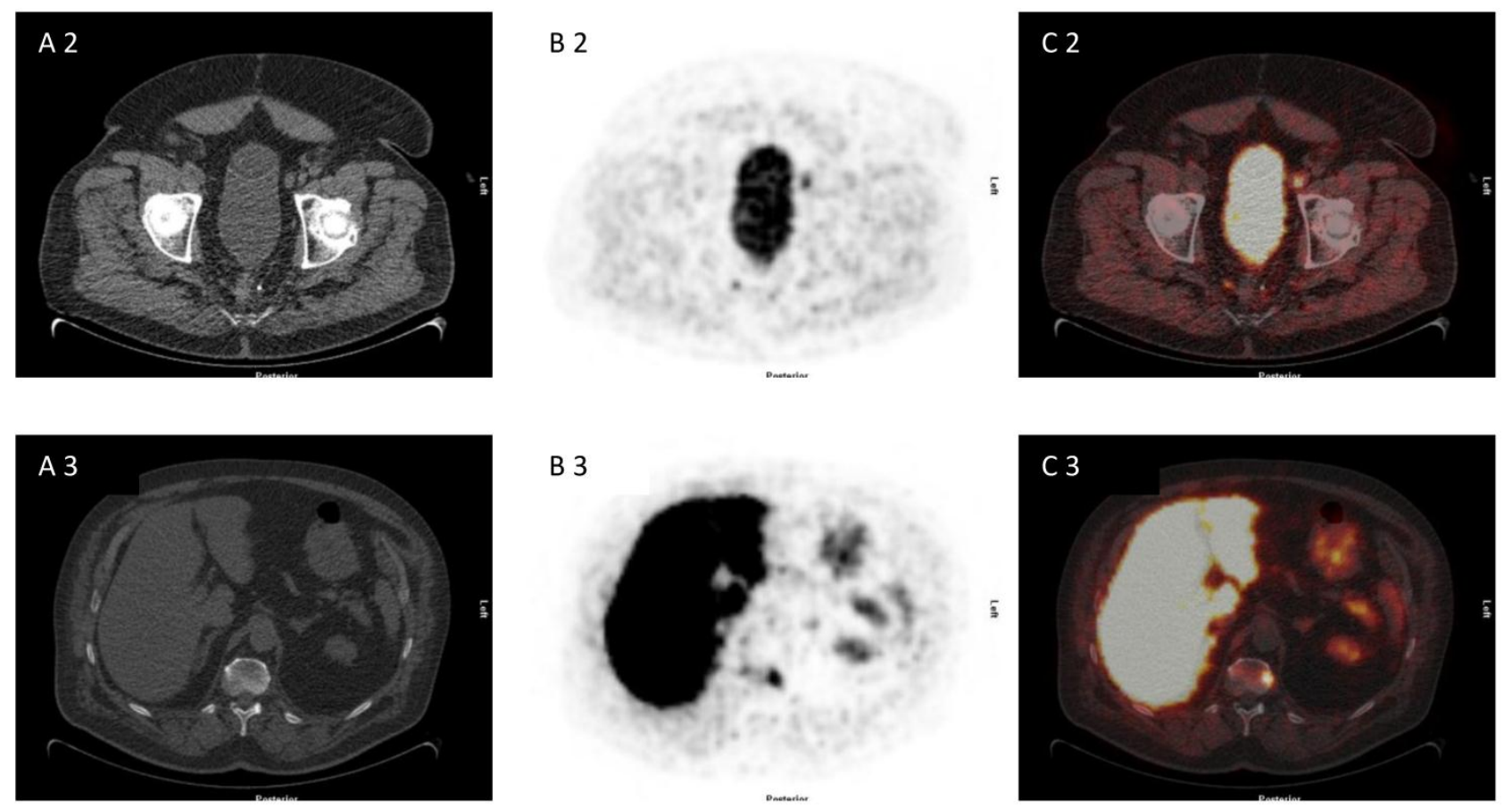

Fig. 3. 75 year old patient under of primary prostate cancer and increasing PSA $>40 \mathrm{ng} / \mathrm{ml}$, referred for [ $\left.{ }^{18} \mathrm{~F}\right] \mathrm{choline} \mathrm{PET} / \mathrm{CT}$ for primary staging due to multiple negative biopies. [ $\left.{ }^{18} \mathrm{~F}\right]$ choline PET/CT revealed advanced disease with multilocular prostate cancer, lymph node metastasis and bone metastasis (A I-3) CT scan, (B I-3) PET scan, (C I-3) PET/CT fused images.

Table I. Diagnostic efficacy of $\left[{ }^{18} \mathrm{~F}\right]$ Choline and $\left[{ }^{11} \mathrm{C}\right]$ Choline PET and PET/CT in patients with primary prostate cancer (modified and updated from [12]). *Sextant-based comparison with histology. **Uptake ratio of lesion to muscle was compared with histology.

\begin{tabular}{|c|c|c|c|c|c|c|c|c|c|}
\hline Tracer & Ref. & Author & Year & Modus & Pts. (n) & Local tumour & & Lymph nodes & \\
\hline & & & & & & Sensitivity (\%) & Specificity (\%) & Sensitivity (\%) & Specificity (\%) \\
\hline \multirow[t]{7}{*}[{}^{18}\mathrm{F}]{$\mathrm{FCH}$} & {$[21]$} & Kwee & 2005 & PET & 17 & 100 & - & - & - \\
\hline & {$[66]$} & Schmid & 2005 & $\mathrm{PET} / \mathrm{CT}$ & 19 & 100 & - & - & - \\
\hline & [63] & Kwee & 2006 & PET & 26 & 100 & - & - & - \\
\hline & {$[62]$} & Husarik & 2008 & $\mathrm{PET} / \mathrm{CT}$ & 43 & 98 & - & 33 & 100 \\
\hline & {$[67]$} & Steuber & 2010 & $\mathrm{PET} / \mathrm{CT}$ & 20 & - & - & 0 & 100 \\
\hline & [59] & Beheshti & 2010 & $\mathrm{PET} / \mathrm{CT}$ & 130 & n.c. & n.c. & 45 & 96 \\
\hline & {$[70]$} & Poulsen & 2010 & $\mathrm{PET} / \mathrm{CT}$ & 25 & - & - & 100 & 95 \\
\hline \multirow[t]{3}{*}[{}^{11}\mathrm{C}]{ Cho } & {$[8]$} & Kotzerke & 2000 & PET & 23 & 100 & - & 50 & 90 \\
\hline & {$[60]$} & de Jong & 2002 & PET & 25 & 100 & - & 80 & 95 \\
\hline & {$[71]$} & de Jong & 2003 & PET & 67 & - & - & 80 & 96 \\
\hline
\end{tabular}




\begin{tabular}{|c|c|c|c|c|c|c|c|c|c|}
\hline Tracer & Ref. & Author & Year & Modus & Pts. (n) & Local tumour & & Lymph nodes & \\
\hline & & & & & & Sensitivity (\%) & Specificity (\%) & Sensitivity (\%) & Specificity (\%) \\
\hline & {$[68]$} & Sutinen & 2004 & PET & 14 & 100 & - & - & - \\
\hline & [23] & Yamaguchi & 2005 & PET & 20 & 100 & - & - & - \\
\hline & [69] & Yoshida & 2005 & PET & 13 & - & - & - & - \\
\hline & {$[24]$} & Farsad ${ }^{*}$ & 2005 & $\mathrm{PET} / \mathrm{CT}$ & 36 & 66 & 81 & - & - \\
\hline & [22] & Reske* & 2006 & $\mathrm{PET} / \mathrm{CT}$ & 26 & 100 & - & - & - \\
\hline & [27] & Scher & 2007 & $\mathrm{PET} / \mathrm{CT}$ & 58 & 86 & 70 & - & - \\
\hline & [26] & Martorana* & 2006 & $\mathrm{PET} / \mathrm{CT}$ & 43 & 66 & 84 & - & - \\
\hline & [25] & Giovacchini* & 2008 & PET/CT & 19 & 72 & 43 & - & - \\
\hline & [65] & Schiavina & 2008 & $\mathrm{PET} / \mathrm{CT}$ & 57 & - & - & 60 & 98 \\
\hline & {$[64]$} & $\mathrm{Li}^{* *}$ & 2008 & $\mathrm{PET} / \mathrm{CT}$ & 49 & 90 & 86 & - & - \\
\hline & [11] & Watanabe & 2010 & PET & 43 & 73 & 59 & - & - \\
\hline & [28] & Souvatzoglou* & 2011 & PET/CT & 43 & 79 & - & - & - \\
\hline Sum & & & & & 816 & & & & \\
\hline Mean & & & & & & 89,4 & 70,5 & 56 & 96.2 \\
\hline Median & & & & & & 99 & 75,5 & 55 & 96 \\
\hline
\end{tabular}

Farsad et al. examined the usefulness of $\left[{ }^{11} \mathrm{C}\right]$ choline PET/CT for imaging of primary prostate cancer correlating imaging studies and histopathologic examinations of axial step sections. Thirty six patients that were included in the study had biopsy-proven prostate cancer and underwent radical prostatectomy and pelvic lymph node dissection after $\left.{ }^{[11} \mathrm{C}\right]$ choline PET/CT. On a sextant basis histopathology was used to evaluate $\left[{ }^{11} \mathrm{C}\right]$ choline uptake with respect to prostate cancer, prostatitis, benign prostatic hyperplasia and high-grade intraepithelial neoplasia (HGPIN). PET detected 108 biopsies with suspicious $\left.{ }^{[11} \mathrm{C}\right]$ choline uptake (of which 94 were located in the area of a tumor) and 108 biopsy cores with normal $\left.{ }^{[11} \mathrm{C}\right]$ choline uptake (of which 49 were false negative), resulting in a sensitivity of $66 \%$ [24]. Scher et al. conducted a study exploring the diagnostic value of $\left[{ }^{11} \mathrm{C}\right]$ choline PET and PET/CT in a group of 58 patients with suspected prostate cancer. Prostate cancer prevalence in this group was $63.8 \%(37 / 58)$. Mean $\mathrm{SUV}_{\max }$ for prostate cancer was $4.3 \pm 1.7$ (2.2-9.8). Mean $\mathrm{SUV}_{\max }$ for patients without prostate carcinoma was $3.3 \pm 0.9(1.4-4.7) \quad(p=0.027)$. Prostate cancers of the 5 patients with negative PET and PET/CT scans demonstrated $\mathrm{SUV}_{\max }$ values between 2.2 and 3.3. $\left[{ }^{11} \mathrm{C}\right]$ choline PET and PET/CT demonstrated a sensitivity of $86.5 \%(32 / 37)$, a positive predictive value of $80.0 \%$, a negative predictive value of $72.2 \%$ and accuracy of $77.6 \%$ [27]. Martorana et al. examined the sensitivity of PET and CT for intraprostatic localization of prostate cancer on the basis of nodular lesions and a transrectal prostate biopsy (12 cores) [26].
PET/CT demonstrated a sensitivity of $83 \%, 66 \%$ and $4 \%$, respectively, for localization of nodular lesions measuring more than $5 \mathrm{~mm}$, for all lesions and lesions smaller than $5 \mathrm{~mm}$, respectively. Logistic regression analysis revealed that only size had an influence on sensitivity. Based on sextant biopsy PET/CT had a slightly better sensitivity than transrectal ultrasound ( $66 \%$ vs. $61 \%, p=0.434)$. For determination of extraprostatic extension, sensitivity of PET/CT was low in comparison with MRI ( $22 \%$ vs. $63 \%, \mathrm{p}=0.001)$ [26]. Giovacchini et al. performed $\left[{ }^{11} \mathrm{C}\right]$ choline PET/CT in 19 patients comparing post-prostatectomy histopathologic axial step sections with $\left[{ }^{11} \mathrm{C}\right]$ choline PET/CT imaging. With a $\mathrm{SUV}_{\max }$ cut-off of $2.5,\left[{ }^{11} \mathrm{C}\right]$ choline PET/CT had a sensitivity of $72 \%$ which concurred with the studies of Farsad et al. [24], Scher et al. [27] and Martorana et al. [26]. Souvatzoglou et al. examined 43 patients with primary prostate cancer comparing imaging and histopathology using a segment-based analysis. They showed that the sensitivity of $\left.{ }^{11} \mathrm{C}\right]$ choline PET/CT depends on the tumor configuration. Prostate segments involved by cancer could be identified in $79 \%$ of the patients using $\left[{ }^{11} \mathrm{C}\right]$ choline PET/CT. Tumor configuration was the only factor significantly influencing tumour prediction $(p<0.001)$ [28].

Therefore there is emerging evidence as discussed by Souvatzoglou et al. that tumor configuration seems to be a major factor influencing the detection of primary prostate cancer. The detection of small and partly 'rind-like` carcinomas (onion ring form of growth) is often not possible [28]. 
Besides the limited sensitivity, the differentiation between benign prostatic hyperplasia (BPH), prostatitis or high-grade intraepithelial neoplasia (HGPIN) is not always possible in primary staging of prostate cancer using choline PET/CT [23-26, 66, 68-69].

Reske et al. showed that choline uptake was significantly higher in prostate cancer in comparison to normal prostate tissue, prostatitis and other benign lesions $(p<0.001)$. (SUVmean of benign prostatic lesion $2.0+/-0.6$; $\mathrm{SUV}_{\text {mean }}$ of prostate cancer 3.5 +/1.3). The authors reported a specificity of $87 \%$ using a $\mathrm{SUV}_{\max }$ threshold of 2.65 [22]. Scher et al. reported a specificity of $61.9 \%(13 / 21)$ for the diagnosis of primary prostate cancer. The authors concluded that a differentiation between benign and malignant lesions is possible in most cases if imaging analysis is mainly based on qualitative criteria. The authors discussed a $\mathrm{SUV}_{\max }$ cut-off of 3.3 for differentiation of benign and malignant lesions (with a sensitivity of $70.3 \%$ and a specificity of $57.1 \%$ ) [27]. Kwee et al. reported a significant higher $S U V_{\max }$ in biopsy proven positive sextants compared to non-malignant sextans (mean value 5.5 vs. 3.3, $\mathrm{p}<0.001$ ). Therefore the authors concluded that differentiation between benign and malignant prostatic lesions was possible using $\left[{ }^{18} \mathrm{~F}\right]$ choline PET. Kwee et al. (2006) also evaluated the efficacy of delayed $\left[{ }^{18} \mathrm{~F}\right]$ choline PET imaging or imaging at two time points for the localization of primary prostate carcinoma (7 minutes and 1 hour). The mean SUV $\max$ for malignant findings significantly increased from 7.6 to 8.6 between early and delayed acquisition (mean retention index $+14 \%$, $95 \%$ confidence interval $6-22 \%$, $\mathrm{p}=0.002)$. The mean $S U V_{\max }$ for presumably benign lesions significantly decreased between the initial and the late image (4.8 to 3.9). The mean ratio between malignant and benign lesions increased significantly (1.4 to 1.8 in the late images $(p=0.0003)$ [63]. Piert et al. examined 14 patients suffering from prostate cancer using $\left.{ }^{11} \mathrm{C}\right]$ choline PET/CT. Tumor-to-background ratios $\mathrm{T}_{\text {mean }} / \mathrm{B}$ - and $\mathrm{T}_{\max } / \mathrm{B}$-were calculated. Lesions with a Gleason score of $4+3$ or higher showed significantly higher $\mathrm{T}_{\text {mean }} / \mathrm{B}$ - and $\mathrm{T}_{\max }$ / B-ratios in comparison to the tumours with a Gleason score of $3+4$ and lower. The authors also reported a correlation between MIB-1/Ki-67-expression, Gleason score and $\mathrm{T}_{\text {mean }} / \mathrm{B}$ - and $\mathrm{T}_{\max } / \mathrm{B}$-ratios. Choline uptake correlated positively with the proliferation index [72]. Giovacchini et al. reported a specificity of $43 \%$ using a SU$\mathrm{V}_{\max }$ cut- off of 2.5 for differentiation between benign and malignant prostatic lesions. The authors found the co-existence of prostatitis, HGPIN and BPH to be a main limitation of their study [25]. Schmid et al., Yoshida et al. and Yamaguchi et al. confirmed these results by showing that there was a significant overlap of choline uptake between $\mathrm{BPH}$ and prostate cancer which resulted in a limited specificity in the detetion of primay prostate cancer using choline PET/CT [23, $66,69]$. Sutinen et al. calculated kinetic parameters on the basis of graphical analysis of the dynamic uptake in the prostate within 30 minutes. The mean $\mathrm{K}_{\mathrm{i}}$-values were $0.205 \pm 0.089 \mathrm{~min}^{-1}(0.128-0.351 ; \mathrm{n}=7)$ and $5.6 \pm 3.2$ $(1.9-15.5 ; \mathrm{n}=15)$ for untreated tumours and $3.5 \pm 1.0$ $(2.0-4.5 ; \mathrm{n}=4)$ and $0.119 \pm 0.076 \mathrm{~min}^{-1}(0.065-0.173 ; \mathrm{n}=2)$ for benign prostatic enlargement. The authors reported a high correlation between the $\mathrm{K}_{\mathrm{i}}$-values and SUV ( $r=0.964, p=0.0005)$ while there was no correlation for $\left[{ }^{11} \mathrm{C}\right]$ Choline uptake in the tumour and grade of differentiation, Gleason-Score, volume of the prostate and PSA value. The authors demonstrated that a high $\left[{ }^{11} \mathrm{C}\right]$ choline uptake not only exists in prostate cancer but also in prostate hyperplasia meaning there is an extensive overlap in $\mathrm{K}_{\mathrm{i}}$-values and SUV [68]. Martorana et al. showed that $S_{U V} V_{\max }$ was significantly higher in malignant lesions compared to benign lesion $(p=0.027)$. However there was no statistically significant difference between false-positive and false-negative findings. Based on sextant biopsy, PET/CT had a slightly better sensitivity than transrectal ultrasound ( $66 \%$ vs. $61 \%, \mathrm{p}=0.434)$ but it was less specific ( $84 \%$ vs. $97 \%, p=0.008$ ) [26]. Farsad et al. confirmed that benign entities such as HGPIN, prostatitis and BPH also show a high choline uptake. The authors reported a specificity of $81 \%$ for the detection of primary prostate cancer that was not significantly different from that with HGPIN [24]. Beheshti et al. examined 130 patients preoperatively using [ $\left.{ }^{18} \mathrm{~F}\right]$ fluorocholine $(\mathrm{FCH}) \mathrm{PET} / \mathrm{CT}$. Differentiation between prostate cancer and prostatitis was not possible due to intense $\mathrm{FCH}$ accumulation of inflammatory lesions [59]. Souvatzoglou et al. confirmed the results concerning limited specificity of choline PET/CT in primary staging of prostate cancer. In their study there was no statistically significant difference between $S U V_{\max }$ of prostate cancer, benign prostate hyperplasia $(\mathrm{p}=0.102)$ or prostatitis $(\mathrm{p}=0.054)$ [28].

In summary, choline PET/CT cannot be recommended as a first-line screening procedure for the diagnosis of primary prostate cancer in men at risk. It might play a role in the detection of clinically suspected prostate cancer with repeatedly negative prostate biopsies.

With respect to lymph node staging only a few studies reported results for sensitivity and specificity of choline PET/CT (see table 1). For lymph node staging in prostate cancer, de Jong et al. showed, that $\left[{ }^{11} \mathrm{C}\right]$ choline PET identified metastatic pelvic lymph nodes with a size between 0.5 and $3 \mathrm{~cm}$ with a mean 
SUV of 4.7 (2.9-9.1). The authors reported 19 correct negative findings in 19 patients without lymph node metastases and one false positive $\left[{ }^{11} \mathrm{C}\right]$ choline enhancement in a lymph node with inflammatory changes [60]. In a further study de Jong et al. explored the accuracy of $\left[{ }^{11} \mathrm{C}\right]$ choline PET/CT in the preoperative non-invasive staging of pelvic lymph nodes in patients with prostate cancer, reporting values of $80 \%$, $96 \%$ and $93 \%$ for sensitivity, specificity and accuracy, respectively [71]. Kotzerke et al. reported sensitivity and specificity of $50 \%$ and $90 \%$, respectively, for $\left[{ }^{11} \mathrm{C}\right]$ choline PET [8]. Schiavina et al. examined 57 patients with biopsy-proven prostate cancer who had intermediate or high risk for lymph node metastases using $\left[{ }^{11} \mathrm{C}\right]$ choline PET/CT prior to prostatectomy and extended pelvic lymph node dissection [65]. $\left[{ }^{11} \mathrm{C}\right]$ choline PET/CT showed a sensitivity of $60 \%$ and a specificity of $98 \%$ for the detection of lymph node metastases. Comparing $\left.{ }^{11} \mathrm{C}\right]$ choline PET/CT findings to nomograms, no statistically significant difference was found. Poulsen et al. examined 25 consecutive patients with primary prostate cancer with $\mathrm{FCH}$ PET/CT. The sensitivity and specificity of $\mathrm{FCH}$ PET/CT for patient based lymph node staging of prostate cancer was $100 \%$ and $95 \%$ [70]. The variation of reported percentage of patients presenting with lymph node metastases with respect to nodal staging can possibly be explained with the differences of the patient cohorts included in the various studies (low risk vs. intermediate vs. high risk patients). Nevertheless, sensitivity of choline PET/CT seems to be low for the detection of small lymph node metastases and micrometastases.

Concerning M-staging, Beheshti et al. and Langsteger et al. examined the use of $\left[{ }^{11} \mathrm{C}\right]-$ and $\left[{ }^{18} \mathrm{~F}\right]$-labelled choline PET/CT as well as $\left[{ }^{18} \mathrm{~F}\right]$ fluoride PET/CT (which reflects blood flow and osteoblastic activity) for imaging of bone metastases of primary prostate cancer as well as locally recurrent prostate cancer. Beheshti et al. examined thirty-eight patients with biopsy-proven prostate cancer (17 of the patients preoperatively and 21 patients referred for post-operative evaluation of suspected recurrence or progression based on clinical algorithms) comparing $\mathrm{FCH}$ and $\left[{ }^{18} \mathrm{~F}\right]$ fluoride (FNa) PET/CT scanning for the detection of bone metastases from primary and recurrent prostate cancer. In the whole group of 38 patients (preoperatively as well as post-operatively) overall sensitivity, specificity and accuracy of PET/CT in the detection of bone metastases in prostate cancer were $74 \%, 99 \%$ and $85 \%$ for $\mathrm{FCH}$ and $81 \%, 93 \%$ and $86 \%$ for $\mathrm{FNa}$, respectively. $\mathrm{FCH}$ PET/CT led to a change in the management in 2 of 38 patients due to the early detection of bone marrow metastases [73].

In another study Beheshti et al. compared the uptake of $\mathrm{FCH}$ in bone metastases in 70 patients (32 preoperatively with biopsy-proven prostate cancer, 38 postoperatively with suspected recurrence of prostate cancer) in comparison to morphologic changes on CT. For all 70 patients (preoperatively as well as postoperatively) sensitivity, specificity and accuracy of $\mathrm{FCH}$ PET/CT in detecting bone metastases from prostate cancer were $79 \%, 97 \%$, and $84 \%$, respectively [74].

In a prospective study Langsteger et al. compared the diagnostic performance of $\mathrm{FCH}$ and $\mathrm{FNa}$ for the detection of bone metastases in 42 patients with prostate cancer and a follow up of at least 6 months. Overall, bone involvement was present in 22 patients and absent in 18. For the whole group of patients (initial staging as well as patients referred for suspicion of recurrence), the patient-based diagnostic performance for $\mathrm{FCH}$ vs. FNa was $91 \%$ vs. $91 \%$ for sensitivity, $89 \%$ vs. $83 \%$ for specificity and $90 \%$ vs. $88 \%$ for accuracy (without statistically significant difference). There was also no significant difference in site-based diagnostic performance in the group of patients referred at initial staging. However, in the group of patients referred for suspicion of recurrence, $\mathrm{FCH}$ was significantly more specific than $\mathrm{FNa}(96 \%$ vs. $91 \%, \mathrm{P}=0.033$ with Obuchowski's correction) while sensitivity was the similar, $89 \%$ [75].

Concerning M-staging of primary and recurrent prostate cancer FCH PET-CT may be superior for the early detection (i.e. bone marrow involvement and early cortical involvement) of metastatic bone disease. In patients with $\mathrm{FCH}$-negative suspicious sclerotic lesions, a second bone-seeking agent (e.g. FNa) might give additional information.

\section{Conclusion and Outlook}

Choline PET/CT is a clinically valuable tool for re-staging patients with increasing PSA serum levels after definitive local therapy. However, at the present time choline PET/CT cannot be recommended as a first-line screening procedure for primary prostate cancer in men at risk due to its limited sensitivity, its dependency on tumor configuration and its limited specificity in differentiating prostate cancer tissue form benign pathologies. Choline PET/CT may be of value for the detection of clinically suspected prostate cancer with multiple negative prostate biopsies. Choline PET/CT plays a role in patient stratification with respect to lymph node involvement for primary surgery and radiation therapy. Therefore the potential role of choline PET/CT in lymph node staging of primary prostate cancer will have to be evaluated in further studies. 
Although considerable progress has been made in the recent years with PET/CT using $\left[{ }^{11} \mathrm{C}\right]-$ and $\left[{ }^{18} \mathrm{~F}\right]$-labelled choline derivates, diagnostic performance still needs to be improved. Many strategies for prostate cancer imaging with novel radiotracers such as bombesin-based tracers or tracers for androgen receptor imaging are being assessed in preclinical studies and in some cases in first clinical feasibility studies. In the future more tumour-specific tracers may increase the sensitivity and specificity for multimodal imaging detection of prostate cancer. Advances in hybrid imaging, especially PET/MR, could also provide improvement in diagnostic accuracy by combining molecular imaging properties of PET with high resolution and excellent soft-tissue contrast of MRI.

\section{Competing Interests}

The authors have declared that no competing interest exists.

\section{References}

1. Jemal A, Siegel R, Ward E, et al. Cancer statistics, 2009. CA Cancer J Clin. 2009; 59: 225-49.

2. Smith RA, Cokkinides V, Eyre HJ. Cancer screening in the United States, 2007: a review of current guidelines, practices, and prospects. CA Cancer J Clin 2007; 57: 90-104.

3. Hofer C, Laubenbacher C, Block $\mathrm{T}$, et al. Fluorine-18-fluorodeoxyglucose positron emission tomography is useless for the detection of local recurrence after radical prostatectomy. Eur Urol 1999; 36: 31-5.

4. Morris MJ, Akhurst T, Osman I, et al. Fluorinated deoxyglucose positron emission tomography imaging in progressive metastatic prostate cancer. Urology 2002; 59: 913-8.

5. Nunez R, Macapinlac HA, Yeung HW, et al. Combined 18F-FDG and 11C-methionine PET scans in patients with newly progressive metastatic prostate cancer. J Nucl Med 2002; 43: 46-55.

6. Albrecht S, Buchegger F, Soloviev D, et al. (11)C-acetate PET in the early evaluation of prostate cancer recurrence. Eur J Nucl Med Mol Imaging 2007; 34: 185-96.

7. Dehdashti F, Picus J, Michalski JM, et al. Positron tomographic assessment of androgen receptors in prostatic carcinoma. Eur J Nucl Med Mol Imaging 2005; 32: 344-50.

8. Kotzerke J, Prang J, Neumaier B, et al. Experience with carbon-11 choline positron emission tomography in prostate carcinoma. Eur J Nucl Med 2000; 27: 1415-9.

9. Larson SM, Morris M, Gunther I, et al. Tumor localization of 16beta-18F-fluoro-5alpha-dihydrotestosterone versus 18F-FDG in patients with progressive, metastatic prostate cancer. J Nucl Med 2004; 45: 366-73.

10. Toth G, Lengyel Z, Balkay L, et al. Detection of prostate cancer with 11C-methionine positron emission tomography. J Urol 2005; 173: 66-9.

11. Watanabe $\mathrm{H}$, Kanematsu $\mathrm{M}$, Kondo $\mathrm{H}$, et al. Preoperative detection of prostate cancer: a comparison with 11C-choline PET, 18F-fluorodeoxyglucose PET and MR imaging. J Magn Reson Imaging 2010; 31: 1151-6.

12. Krause BJ, Souvatzoglou M, Treiber U. Imaging of prostate cancer with PET/CT and radioactively labeled choline derivates. Urol Oncol 2011; epub.
13. Ackerstaff E, Glunde K, Bhujwalla ZM. Choline phospholipid metabolism: a target in cancer cells? J Cell Biochem. 2003; 90: 525-33.

14. Casciani E, Gualdi GF. Prostate cancer: value of magnetic resonance spectroscopy $3 \mathrm{D}$ chemical shift imaging. Abdom Imaging 2006; 31: 490-9.

15. Ramirez de Molina A, Penalva V, Lucas L, et al. Regulation of choline kinase activity by Ras proteins involves Ral-GDS and PI3K. Oncogene 2002; 21: 937-46.

16. Ratnam S, Kent C. Early increase in choline kinase activity upon induction of the H-ras oncogene in mouse fibroblast cell lines. Arch Biochem Biophys 1995; 323: 313-22.

17. Ackerstaff E, Pflug BR, Nelson JB, et al. Detection of increased choline compounds with proton nuclear magnetic resonance spectroscopy subsequent to malignant transformation of human prostatic epithelial cells. Cancer Res 2001; 61: 3599-603.

18. Hara T, Bansal A, DeGrado TR. Choline transporter as a novel target for molecular imaging of cancer. Mol Imaging 2006; 5: 498-509.

19. Katz-Brull R, Degani H. Kinetics of choline transport and phosphorylation in human breast cancer cells: NMR application of the zero trans method. Anticancer Res 1996; 16: 1375-80.

20. Souvatzoglou M, Gaertner FC, Schwarzenböck S, et al. PET/CT for the diagnosis, staging and restaging of prostate cancer. Imaging Med 2011; in press.

21. Kwee SA, Coel MN, Lim J, et al. Prostate cancer localization with 18fluorine fluorocholine positron emission tomography. J Urol 2005; 173: 252-5.

22. Reske SN, Blumstein NM, Neumaier B, et al. Imaging prostate cancer with 11C-choline PET/CT. J Nucl Med 2006; 47: 1249-54.

23. Yamaguchi $\mathrm{T}$, Lee J, Uemura $\mathrm{H}$, et al. Prostate cancer: a comparative study of 11C-choline PET and MR imaging combined with proton MR spectroscopy. Eur J Nucl Med Mol Imaging 2005; 32: 742-8.

24. Farsad M, Schiavina R, Castellucci P, et al. Detection and localization of prostate cancer: correlation of (11)C-choline PET/CT with histopathologic step-section analysis. J Nucl Med 2005; 46: 1642-9.

25. Giovacchini G, Picchio M, Coradeschi E, et al. [(11)C]choline uptake with PET/CT for the initial diagnosis of prostate cancer: relation to PSA levels, tumour stage and anti-androgenic therapy. Eur J Nucl Med Mol Imaging 2008; 35: 1065-73.

26. Martorana G, Schiavina R, Corti B, et al. 11C-choline positron emission tomography/computerized tomography for tumor localization of primary prostate cancer in comparison with 12-core biopsy. J Urol 2006; 176: 954-60.

27. Scher B, Seitz M, Albinger W, et al. Value of 11C-choline PET and PET/CT in patients with suspected prostate cancer. Eur J Nucl Med Mol Imaging 2007; 34: 45-53.

28. Souvatzoglou M, Weirich G, Schwarzenboeck S, et al. The Sensitivity of [11C]Choline PET/CT to Localize Prostate Cancer Depends on the Tumor Configuration. Clin Cancer Res 2011; 17: 3751-9.

29. Wolf JS Jr., Cher M, Dall'era M, et al. The use and accuracy of cross-sectional imaging and fine needle aspiration cytology for detection of pelvic lymph node metastases before radical prostatectomy. J Urol 1995; 153: 993-9.

30. Fuchsjager M, Shukla-Dave A, Akin O, et al. Prostate cancer imaging. Acta Radiol 2008; 49(1):107-20.

31. O'Dowd GJ, Veltri RW, Orozco R, et al. Update on the appropriate staging evaluation for newly diagnosed prostate cancer. J Urol 1997; 158: 687-98.

32. Mullerad $M$, Hricak $H$, Kuroiwa $K$, et al. Comparison of endorectal magnetic resonance imaging, guided prostate biopsy and digital rectal examination in the preoperative anatomical localization of prostate cancer. J Urol 2005; 174: 2158-63. 
33. Hricak H, Choyke PL, Eberhardt SC, et al. Imaging prostate cancer: a multidisciplinary perspective. Radiolog. 2007; 243: 28-53.

34. Sella T, Schwartz LH, Swindle PW, et al. Suspected local recurrence after radical prostatectomy: endorectal coil MR imaging. Radiology. 2004; 231: 379-85.

35. Bloch BN, Furman-Haran E, Helbich TH, et al. Prostate cancer: accurate determination of extracapsular extension with high-spatial-resolution dynamic contrast-enhanced and T2-weighted MR imaging--initial results. Radiology 2007; 245: 176-85.

36. Futterer JJ. MR imaging in local staging of prostate cancer. Eur J Radiol 2007; 63: 328-34.

37. Wefer AE, Hricak H, Vigneron DB, et al. Sextant localization of prostate cancer: comparison of sextant biopsy, magnetic resonance imaging and magnetic resonance spectroscopic imaging with step section histology. J Urol 2000; 164: 400-4.

38. Mazaheri Y, Shukla-Dave A, Hricak H, et al. Prostate cancer: identification with combined diffusion-weighted MR imaging and 3D $1 \mathrm{H}$ MR spectroscopic imaging--correlation with pathologic findings. Radiology 2008; 246: 480-8.

39. Testa C, Schiavina R, Lodi R, et al. Prostate cancer: sextant localization with MR imaging, MR spectroscopy, and 11C-choline PET/CT. Radiology 2007; 244: 797-806.

40. Eschmann SM, Pfannenberg AC, Rieger A, Aschoff P, Muller $\mathrm{M}$, Paulsen F, et al. Comparison of 11C-choline-PET/CT and whole body-MRI for staging of prostate cancer. Nuklearmedizin. 2007; 46: 161-8.

41. Heesakkers RA, Hovels AM, Jager GJ, et al. MRI with a lymph-node-specific contrast agent as an alternative to CT scan and lymph-node dissection in patients with prostate cancer: a prospective multicohort study. Lancet Oncol 2008; 9: 850-6.

42. Eiber M, Beer AJ, Holzapfel K, et al. Preliminary results for characterization of pelvic lymph nodes in patients with prostate cancer by diffusion-weighted MR-imaging. Invest Radiol 2010; 45: 15-23.

43. Beer AJ, Eiber M, Souvatzoglou M, et al. Restricted water diffusibility as measured by diffusion-weighted MR imaging and choline uptake in (11)C-choline PET/CT are correlated in pelvic lymph nodes in patients with prostate cancer. Mol Imaging Biol 2011; 13: 352-61.

44. Effert PJ, Bares R, Handt S, et al. Metabolic imaging of untreated prostate cancer by positron emission tomography with 18fluorine-labeled deoxyglucose. J Urol 1996; 155: 994-8.

45. Jadvar H. Prostate cancer: PET with 18F-FDG, 18F- or 11C-acetate, and 18F- or 11C-choline. J Nucl Med 2011; 52: 81-9.

46. Liu IJ, Zafar MB, Lai YH, et al. Fluorodeoxyglucose positron emission tomography studies in diagnosis and staging of clinically organ-confined prostate cancer. Urology 2001; 57: 108-11.

47. Fanti S, Nanni $C$, Ambrosini $V$, et al. PET in genitourinary tract cancers. Q J Nucl Med Mol Imaging 2007; 51: 260-71.

48. Oyama N, Akino $H$, Suzuki $Y$, et al. The increased accumulation of [18F]fluorodeoxyglucose in untreated prostate cancer. Jpn J Clin Oncol 1999; 29: 623-9.

49. Melchior SW, Fichtner J, Jones J. Changes in fluorodeoxyglucose (FDG) uptake measured by positron emission tomography (PET) in prostate cancer (CaP) patients following androgen withdrawal. J Urol 1999; 161: 297.

50. Jadvar H, Xiankui L, Shahinian A, et al. Glucose metabolism of human prostate cancer mouse xenografts. Mol Imaging 2005; 4: 91-7.

51. Schoder H, Larson SM. Positron emission tomography for prostate, bladder, and renal cancer. Semin Nucl Med 2004; 34: 274-92.

52. Yoshimoto M, Waki A, Yonekura Y, et al. Characterization of acetate metabolism in tumor cells in relation to cell proliferation: acetate metabolism in tumor cells. Nucl Med Biol 2001; 28: 117-22.

53. Swinnen JV, Van Veldhoven PP, Timmermans L, et al. Fatty acid synthase drives the synthesis of phospholipids partitioning into detergent-resistant membrane microdomains. Biochem Biophys Res Commun 2003; 302: 898-903.

54. Oyama N, Akino H, Kanamaru $\mathrm{H}$, et al. 11C-acetate PET imaging of prostate cancer. J Nucl Med 2002; 43: 181-6.

55. Kato T, Tsukamoto E, Kuge $Y$, et al. Accumulation of [11C]acetate in normal prostate and benign prostatic hyperplasia: comparison with prostate cancer. Eur J Nucl Med Mol Imaging 2002; 29: 1492-5.

56. Wachter S, Tomek S, Kurtaran A, et al. 11C-acetate positron emission tomography imaging and image fusion with computed tomography and magnetic resonance imaging in patients with recurrent prostate cancer. J Clin Oncol 2006; 24: 2513-9.

57. Jambor I, Borra R, Kemppainen J, et al. Functional imaging of localized prostate cancer aggressiveness using 11C-acetate PET/CT and 1H-MR spectroscopy. J Nucl Med 2010; 51: 1676-83.

58. Shiiba M, Ishihara K, Kimura G, et al. Evaluation of primary prostate cancer using (11)C-methionine-PET/CT and. Ann Nucl Med 2011.

59. Beheshti M, Imamovic L, Broinger G, et al. $18 \mathrm{~F}$ choline PET/CT in the preoperative staging of prostate cancer in patients with intermediate or high risk of extracapsular disease: a prospective study of 130 patients. Radiology 2010; 254: 925-33.

60. de Jong IJ, Pruim J, Elsinga PH, et al. Visualization of prostate cancer with 11C-choline positron emission tomography. Eur Urol 2002; 42: 18-23.

61. de Jong IJ, Pruim J, Elsinga PH, et al. 11C-choline positron emission tomography for the evaluation after treatment of localized prostate cancer. Eur Urol 2003; 44: 32-8.

62. Husarik DB, Miralbell R, Dubs M, et al. Evaluation of [(18)F]-choline PET/CT for staging and restaging of prostate cancer. Eur J Nucl Med Mol Imaging. 2008; 35: 253-63.

63. Kwee SA, Wei H, Sesterhenn I, et al. Localization of primary prostate cancer with dual-phase $18 \mathrm{~F}$-fluorocholine PET. J Nucl Med 2006; 47: 262-9.

64. Li X, Liu Q, Wang M, et al. C-11 choline PET/CT imaging for differentiating malignant from benign prostate lesions. Clin Nucl Med 2008; 33: 671-6.

65. Schiavina R, Scattoni V, Castellucci $\mathrm{P}$, et al. 11C-choline positron emission tomography/computerized tomography for preoperative lymph-node staging in intermediate-risk and high-risk prostate cancer: comparison with clinical staging nomograms. Eur Urol 2008; 54: 392-401.

66. Schmid DT, John H, Zweifel R, et al. Fluorocholine PET/CT in patients with prostate cancer: initial experience. Radiology 2005; 235: 623-8.

67. Steuber T, Schlomm $T$, Heinzer $H$, et al. [F(18)]-fluoroethylcholine combined in-line PET-CT scan for detection of lymph-node metastasis in high risk prostate cancer patients prior to radical prostatectomy: Preliminary results from a prospective histology-based study. Eur J Cancer 2010; 46: 449-55.

68. Sutinen E, Nurmi M, Roivainen A, et al. Kinetics of [(11)C]choline uptake in prostate cancer: a PET study. Eur J Nucl Med Mol Imaging 2004; 31: 317-24.

69. Yoshida S, Nakagomi K, Goto S, et al. 11C-choline positron emission tomography in prostate cancer: primary staging and recurrent site staging. Urol Int 2005; 74: 214-20.

70. Poulsen MH, Bouchelouche $\mathrm{K}$, Gerke $\mathrm{O}$, et al. [18F]-fluorocholine positron-emission/computed tomography for lymph node staging of patients with prostate cancer: 
preliminary results of a prospective study. BJU Int 2010; 106: 639-43.

71. de Jong IJ, Pruim J, Elsinga PH, et al. Preoperative staging of pelvic lymph nodes in prostate cancer by 11C-choline PET. J Nucl Med 2003; 44: 331-5.

72. Piert M, Park H, Khan A, et al. Detection of aggressive primary prostate cancer with 11C-choline PET/CT using multimodality fusion techniques. J Nucl Med 2009; 50: 1585-93.

73. Beheshti M, Vali R, Waldenberger P, et al. Detection of bone metastases in patients with prostate cancer by $18 \mathrm{~F}$ fluorocholine and 18F fluoride PET-CT: a comparative study. Eur J Nucl Med Mol Imaging 2008; 35: 1766-74.

74. Beheshti M, Vali R, Waldenberger P, et al. The use of F-18 choline PET in the assessment of bone metastases in prostate cancer: correlation with morphological changes on CT. Mol Imaging Biol 2010; 12: 98-107.

75. Langsteger W, Balogova S, Huchet V, et al. Fluorocholine (18F) and sodium fluoride (18F) PET/CT in the detection of prostate cancer: prospective comparison of diagnostic performance determined by masked reading. Q J Nucl Med Mol Imaging 2011; 55: 448-57. 